\title{
THE EFFECTS OF EXERCISE AND PHYSICAL ACTIVITY ON DEPRESSION LEVELS IN GREEK ADULT POPULATION
}

Christine Gkatsou ${ }^{1}$, Constantina Katsora ${ }^{2}$, Stylianos Kaprinis ${ }^{3 i}$

'Department of Sports Management, Faculty of Human Movement and Quality of Life, University of Peloponnese, Greece

2Department of Sports Management, Faculty of Human Movement and Quality of Life, University of Peloponnese, Greece

${ }^{3}$ Department of Sports Management, Faculty of Human Movement and Quality of Life, University of Peloponnese, Greece

\begin{abstract}
:
Depression constitutes the most common mental disorder and is associated with problems of emotional, physical and cognitive nature, causing a decrease in well-being, placing a strain on mental health, which ultimately threatens the quality of life. In fact, it tends to become the second most important cause of morbidity and disability in the world after ischemic heart disease. At the same time, exercise and physical activity present as a viral determining factor in the effort to halt the prevalence of the disease. This study examined the relationship between weekly physical activity and depression levels in a sample of seventy Greek adult citizens. Participants completed the Beck Depression Inventory-II (BDI-II) and the Godin Leisure-Time Exercise Questionnaire (GLTEQ). The two questionnaires demonstrated high reliability, and participants who demonstrated a high degree of exercise showed a minimal degree of depression. Using linear regression, it was evident that the effect of physical activity on depression was statistically significant, as the increase in physical activity corresponded with a decrease in the degree of depression. The findings of this study support the view that exercise is an effective proposition for preventing and treating depression.
\end{abstract}

Keywords: exercise, physical activity, depression

i Correspondence: email skaprinis@yahoo.gr skaprinis@uop.gr 


\section{Introduction}

According to the World Health Organization (W.H.O, 2017) 4.4\% of the world's population, about 350 million people, suffer from depression. In Europe, this translates as over 40 million citizens, and it is estimated that in the future $17 \%$ of the population will experience a depressive episode at least once in their lives (W.H.O, 2017). In Greece, $4.7 \%$ of the population suffers from this mental disorder, with 7 out of 10 being women $(67.0 \%)$ and 3 out of 10 men (33.0\%) (Hellenic Statistic Authority, 2016). In general, women are twice as likely to experience a depressive episode, compared to men (Cellano \& Huffman, 2011; Clark et al, 2006; Jonsson et al, 2010). Depression is now considered the most common mental disorder and is associated with emotional, physical and cognitive problems and more commonly with a decrease in well-being, increased functional disabilities and medical care services. Furthermore, the World Health Organization (W.H.O. 2009) estimates that, by the end of 2020, depression will constitute the second most important cause of morbidity and disability in the world after ischemic heart disease. At the same time, exercise and physical activity present as a viral determining factor in the effort to abridge the spread of the disease. Sport may have an assisting and auxiliary role, along the side of other therapeutic approaches. In fact, according to Wipfli, Landers, Nagoshi and Ringenbach (2011), sport is deemed to be the best nonpharmaceutical intervention in the treatment of depression. This study investigated the relationship between weekly physical activity and depression levels in a sample of 70 Greek adult citizens.

\section{Literature Review}

\subsection{Depression}

The World Health Organization (W.H.O, 2012) defines depression as a common mental disorder characterized by sadness, loss of interest or pleasure, decreased energy, feelings of guilt or low self-esteem, troubled sleep or appetite, feelings of fatigue and poor concentration, which can be long-term and/or repetitive. This mental stress causes severe limitations and can significantly affect a person in their daily life (Cellano \& Huffman, 2011). Depression causes, to a pervasive extent, reduced productivity in the workplace while burdening the healthcare systems with several billion dollars due to the expense of antidepressant drugs and psychotherapies (Craft \& Perna, 2004).

According to the American Psychiatric Association (A.P.A, 2013) and the Diagnostic and Statistical Manual of Mental Disorders (DSM-IV) diagnostic tool, subjects who are suffering from depression are faced with mobility problems, since their condition is characterized by a negative attitude, persistent sadness, loss of interest in activities that people usually enjoy. They, also, frequently, experience feelings of fatigue, psychomotor retardation and a desire to stay in bed for a prolonged period of time while avoiding the company of others. Finally, they experience feelings of anxiety, low selfesteem, guilt, obsolescence and might exhibit suicidal tendencies. Genetic factors 
(heritage), biological (CNS diseases, neurotransmitters) and psychosocial factors (personality type, etc.) constitute the most common factors that can lead to depression (Hapel, et al., 2008; Leppanen, 2006; Sadock et al, 2015). People with low self-confidence, oversensitivity, pessimism, perfectionism, tendencies of social isolation and/or dependence on others tend to be more prone to the onset of depression (Raphael, 2000).

\subsection{Benefits of Exercise in Mental Health}

Sport is inextricably linked to parameters such as physical and mental well-being, while it also constitutes one of the main pillars of the concept of quality of life. Exercise has anxiolytic and antidepressant properties (Baybak et al, 2000; Landers \& Arent, 2007; LeUnes, 2008; Salmon, 2000; Wipfli et al, 2011), helps defuse stressors and promotes mental health and well-being in general (Berger \& Tobar, 2007; Biddle, Mutrie \& Gorely, 2015; Gary et al, 2010; Hassmén, et al, 2002). As a matter of fact, surveys (Biddle et al, 2000; Richardson et al, 2005) point out that exercise is a more efficient option for preventing and treating mental disorders than individual or group psychotherapy.

Psychological variables affected by the involvement in sport include an increase in a person's level of self-esteem and self-confidence (Ekeland et al, 2005; Guszkowska, 2004; Netz et al, 2005; Weinberg \& Gould, 2011) and improving body-related self-image (Bodin \& Martinsen, 2004; Hagger et al, 2001). In fact, the effect of exercise programs on mental euphoria is not encountered solely during exercise but also, releases a delayed anxiolytic effect on the subject (Theodorakis, 2016). In particular, by improving cardiovascular function and the secretion of chemicals within the body caused by exercise (dopamine, serotonin, norepinephrine) there is a positive effect on the mood of the person exercising (Guszkowska, 2004). Another interpretation (Theodorakis, 2016) correlates improving the mood of the individual with physical activity by increasing vitality, which in turn, is responsible for the occurrence of pleasant feelings in the person who exercises systematically.

\subsection{Exercise as a Therapeutic Intervention for Depression}

Physical activity has been widely used in the context of a large number of interventional programs aimed at the rehabilitation of mental disorders, in the form of escorts and auxiliary function. However, it is argued (Biddle, Mutrie \& Gorely, 2015) that physical activity as such is not able to act as a treatment for mental health disorders, with the auxiliary role nevertheless, becoming crucial. A Biddle et al (2008) study found that patients who exercised experienced fewer relapses in depressive episodes compared to patients receiving exclusively pharmaceutical relapse. Studies (Osborn, 2001; Paluska \& Schwenk, 2000) have found that aerobic exercise helps relieve mild and moderate depression by reinforcing the individuals' daily routines and increasing interactions with others. In another study (Dimeo et al, 2001) the effect of exercise on a treadmill for 30 minutes per day and for a total period of 10 consecutive days was assessed in depressed patients and showed a statistically significant reduction in symptoms and an improvement in the clinical picture of subjects with depression. In her research, Roh 
(2016) examined the effect of physical exercise on the resilience of the personality of subjects with depression after a 16-week interventional program using Pilates. There has been a noteworthy increase in variables such as self-confidence, self-image, anger management and communication skills, resulting in a sharp reduction in some symptoms of depression. A similar positive connection between physical activity and self-esteem was also identified in their research by Dopp et al, (2012). The positive contribution of exercise regarding improving the subjects' mental state and resulting in "happiness", is supported by the findings of Broman-Fulks \& Storey (2008) in a study concerning neurophysiological changes in exercise in people with depression. The mentioned study concluded that exercise can contribute effectively to lowering the anxiety levels, which is both a manifestation of symptoms and an aggravating factor in depression. Therefore, stress reduction ensures the stability of the mental state of people with depression and reduces its symptoms. In fact, studies such as that of DiLorenzo et al. (1999) argue that the benefits of reducing depression levels, reducing anxiety and uplifting self-image have a long-term duration. In particular, the 12-week survey participants seem to have maintained the benefits they gained in the mentioned areas for a period of time estimated to be twelve months later. Finally, research (Olson et al, 2017) observed a positive correlation between physical activity and cognitive control in people with depression. In particular, the research assessed the effect of aerobic exercise on cognitive control of people with major depressive episodes over an 8-week period. According to the results, there was a statistically significant improvement in cognitive control.

\subsection{Scope of Research}

The purpose of this research was to study physical activity levels in an adult population, and to examine their relation to depression levels based on their self-reports.

\section{Material and Methods}

\subsection{Sample}

The study sample consisted of 70 participants, all legal (adults over 18 years of age). The criteria for selecting the sample were for participants to be engaged in some form physical activity, as well as not to have a diagnosis of neurological or psychological disorders. The survey involved 70 people, with an average age of 27.5 years, with a minimum age of 18 years and a maximum age of 46 years (standard deviation of 7.36 years). In numbers, $53 \%$ of the sample were male while $47 \%$ were female. Also, $24 \%$ were high school graduates, $49 \%$ were university graduates, $24 \%$ had a master's degree and $3 \%$ had a Doctorate. Moreover, $60 \%$ of the sample were employed, while the remaining $40 \%$ were unemployed and/or students. 


\subsection{Data Collection Tools}

For the purposes of the study, (a) the Beck Depression Inventory questionnaire - Beck BDI-II (Beck, Steer \& Brown 1996), (b) the Godin Leisure Time Exercise Questionnaire GLTEQ (Godin \& Shephard, 1985) were used. In Beck Depression Inventory, the overall depression score is calculated by summing up the answers to the 21 questions.

The maximum score that can be obtained in the questionnaire is 63. Scores up to 13 indicate a minimum level of depression, scores from 14 to 19 indicate a low level of depression, scores from 20 to 28 indicate a moderate depression, and scores above 28 indicate the existence of severe depression. Similarly, in the Godin Leisure Time Exercise Questionnaire, overall scores above 23 indicate a high degree of exercise, scores from 14 to 23 indicate a moderate degree of exercise, and scores below 14 indicate a low degree of physical activity.

\subsection{Statistical Analysis}

The statistical analysis was performed through the 25th edition of the SPSS program. Descriptive statistics were performed using both frequencies and percentages as well as the calculation of an average versus standard deviations, the reliability coefficients of the two questionnaires was calculated as well and it was verified that depression and weekly exercise data follow normal distribution using the Kolmogorov-Smirnov Test, which indicated that the data deviated from normal distribution. For the examination of the research cases, non-parametric statistical tests were used, since they do not require the data to follow the normal distribution.

To examine the relationship between exercise and depression levels, a Spearman rho correlation was initially established between the degree of weekly physical exercise and the degree of depression. The potential causal effect of that weekly physical exercise was then examined, as an independent variable, on the subjects' depression levels, as a dependent variable using linear regression.

\section{Results and Discussion}

Table 1 shows the Mean (M) and Standard Deviations (SD) in all Beck Depression Inventory (Beck BDI II) queries. Participants showcased low scores on depression questions.

On the Godin Leisure Time Questionnaire scale, on average, the sample was engaged in 1.66 weekly 15-minute high-intensity exercises, 1.96 moderate-intensity exercises and 2.34 mild intensity exercises per week (Table 2). 
Table 1: Beck Depression Inventory - BDI-II item descriptive

\begin{tabular}{|c|l|c|c|}
\hline & & (M) & ( SD) \\
\hline 1 & Sadness & 0.36 & 0.539 \\
\hline 2. & Pessimism & 0.23 & 0.516 \\
\hline 3 & Past failure & 0.20 & 0.469 \\
\hline 4 & Loss of pleasure & 0.21 & 0.478 \\
\hline 5 & Guilty feelings & 0.20 & 0.437 \\
\hline 6 & Punishment feelings & 0.17 & 0.416 \\
\hline 7 & Self-dislike & 0.19 & 0.427 \\
\hline 8 & Self-criticism & 0.33 & 0.583 \\
\hline 9 & Suicidal thoughts or wishes & 0.09 & 0.282 \\
\hline 10 & Crying & 0.13 & 0.378 \\
\hline 11 & Agitation & 0.21 & 0.508 \\
\hline 12 & Loss of interest & 0.17 & 0.481 \\
\hline 13 & Indecisiveness & 0.14 & 0.391 \\
\hline 14 & Worthlessness & 0.14 & 0.427 \\
\hline 15 & Loss of Energy & 0.26 & 0.606 \\
\hline 16 & Changes in sleeping pattern & 0.26 & 0.582 \\
\hline 17 & Irritability & 0.13 & 0.337 \\
\hline 18 & Change in appetite & 0.09 & 0.282 \\
\hline 19 & Concentration difficulty & 0.07 & 0.259 \\
\hline 20 & Tiredness or fatigue & 0.13 & 0.339 \\
\hline 21 & Loss of interest of sex & 0.10 & 0.347 \\
\hline
\end{tabular}

Table 2: Godin Leisure Time Exercise Questionnaire items descriptive

\begin{tabular}{|c|l|c|c|}
\hline & \multicolumn{1}{|c|}{} & M & SD \\
\hline 1 & $\begin{array}{l}\text { Strenuous Exercise (Heart Beats Rapidly) (e.g., running, jogging, hockey, football, } \\
\text { soccer, squash, basketball, cross country skiing, judo, roller skating, vigorous } \\
\text { swimming) }\end{array}$ & 1.66 & 1.202 \\
\hline 2 & $\begin{array}{l}\text { Moderate Exercise (Not Exhausting) (e.g., fast walking, baseball, tennis, easy } \\
\text { bicycling, volleyball, badminton, easy swimming, alpine skiing, popular and folk } \\
\text { dancing) }\end{array}$ & 1.96 & 1.160 \\
\hline 3 & $\begin{array}{l}\text { Mild/Light Exercise (Minimal Effort) (e.g., yoga, archery, fishing from river bank, } \\
\text { bowling, horseshoes, golf, easy walking) }\end{array}$ & 2.34 & 1.075 \\
\hline
\end{tabular}

\subsection{Reliability Analysis and Average Scores of Depression and Weekly Exercise}

Cronbach's alpha (a) reliability index for the Beck BDI-II depression questionnaire was high and therefore, acceptable with $\mathrm{a}=0.80$ (21 queries). Based on the reliability analysis, the sum of the answers to the depression questions was calculated. In addition, regarding the weekly exercise in leisure time Cronbach's alpha reliability index was high and acceptable with $\mathrm{a}=0.84$ ( 3 queries). The overall weekly leisure time physical activity score was calculated on the basis of the equation (Strenuous exercise $\times 9)+($ Moderate exercise $x$ 5) $+($ Mild/Light exercise x 3) (Table 3). On average, the degree of depression in the subjects was minimal (Beck, Steer \& Brown, 1996), with an average of 3.8. The overall weekly physical activity score was an average of 31.7 indicating a high degree of exercise 
(Godin, 2011). Furthermore, data on depression and weekly exercise did not follow the normal distribution ( $\mathrm{p}<0,200$, based on the Lilliefors statistical significance correction).

Table 3: Mean (M), Standard Deviation (SD),

Cronbach's alpha of depression and weekly exercise

\begin{tabular}{|c|c|c|c|c|c|c|c|c|}
\hline & \multirow[t]{2}{*}{$\mathbf{M}$} & \multirow[t]{2}{*}{ SD } & \multirow[t]{2}{*}{$\begin{array}{c}\text { Cronbach's } \\
\text { Alpha }\end{array}$} & \multirow[t]{2}{*}{$\begin{array}{l}\text { Number of } \\
\text { Questions }\end{array}$} & \multicolumn{3}{|c|}{$\begin{array}{c}\text { Test of Normality } \\
\text { Kolmogorov-Smirnov }\end{array}$} \\
\hline & & & & & & Statistic & df & p \\
\hline 1 & $\begin{array}{l}\text { Beck Depression } \\
\text { Inventory - BDI-II }\end{array}$ & 3.80 & 4.193 & 0.803 & 21 & 0.209 & 70 & $<0.0005$ \\
\hline 2. & $\begin{array}{l}\text { Godin Leisure Time } \\
\text { Exercise Questionnaire }\end{array}$ & 31.73 & 17.620 & 0.844 & 3 & 0.190 & 70 & $<0.0005$ \\
\hline
\end{tabular}

\subsection{Examination of Research Cases}

Regarding the examination of the research hypothesis and whether there is a statistically significant effect of exercise on the depression levels of the sample, a non-parametric check of Spearman rho correlation on the degree of depression and weekly physical activity was performed. A statistically significant and negative relationship was found between the two factors ( $r h o=-0.43, \mathrm{p}<0.01$ ). In particular, when weekly physical activity increases, the degree of depression decreases accordingly and vice versa (Table 4).

Table 4: Correlation of depression and exercise

\begin{tabular}{|l|l|c|}
\hline & & Weekly Leisure Exercise (Godin GLTEQ) \\
\hline \multirow{2}{*}{ Depression Levels Beck II } & Rho & $-0.425^{*}$ \\
\cline { 2 - 3 } & $\mathrm{p}$ & $<0.0005$ \\
\cline { 2 - 3 } & $\mathrm{N}$ & 70 \\
\hline${ }^{*} \mathrm{p}<0.01$ & \multicolumn{2}{|c|}{} \\
\hline
\end{tabular}

Considering the fact that there is a statistically significant correlation between the two factors, a linear regression was performed with the degree of depression as a dependent variable and the weekly exercise as an independent predictive variable. The model was statistically significant $(\mathrm{F}(1.69)=7.51, \mathrm{p}=0.008)$, demonstrating that the data fit the linear regression model. Table 5 presents the summary of the model. The multiple regression coefficient was medium with $\mathrm{R}=0.32$, while the rate of observed variation in the degree of depression explained by weekly physical activity was low, with 9.9\% (R2=0.099).

Table 5: Linear regression model summary

\begin{tabular}{|c|c|c|c|c|}
\hline Model & $\mathbf{R}$ & $\mathbf{R}^{\mathbf{2}}$ & Adjusted $\mathbf{R}^{\mathbf{2}}$ & Standard error of estimate \\
\hline 1 & 0.315 & 0.099 & 0.086 & 4.008 \\
\hline
\end{tabular}

Table 6 effectively shows the predictive strength of total weekly exercise in the context of depression. Total weekly physical activity was a statistically significant predictor of depression $(p=0.008)$, where the one-unit increase in total weekly physical activity 
corresponds with a slight decrease of 0.08 points in the degree of depression. The equation of the linear regression model is: Degree of Depression $=6,181-0,075{ }^{*}$ Total Weekly Exercise.

Table 6: Weekly exercise as a predictive factor

\begin{tabular}{|c|l|c|c|c|c|c|}
\hline & Model & \multicolumn{2}{|c|}{ Non Standard Factors } & \multicolumn{2}{|c|}{ Standard Factor } \\
\hline & & B & SE B & Beta & $\mathbf{t}$ & $\mathbf{p}$ \\
\hline 1 & & 6.181 & 0.992 & & 6.230 & 0.000 \\
\hline 2. & Weekly Exercise (Godin GLTEQ) & -0.075 & 0.027 & -0.315 & -2.741 & 0.008 \\
\hline
\end{tabular}

As a result, the research hypothesis was acceptable and there was a statistically significant and negative relationship between the degree of physical activity and the level of depression in the subjects.

\section{Discussion}

This study examined the effect of physical activity on depression levels of 70 adult citizens. The total weekly physical activity of the sample had an average of 31.7, a score that is higher than 23 points and indicates the existence of a high degree of weekly exercise (Godin, 2011; Godin \& Shephard, 1985). The participants' depression rate was particularly low with an average of 3.8, with a limit of up to 13 points (Beck, Steer \& Brown, 1996). It was found that there was a statistically significant negative correlation between depression and weekly exercise, leading to the conclusion that when the frequency of physical activity is increased, the degree of depression in the sample is decreased and vice versa.

These findings also confirm the conclusions of preceding research that has shown a statistically significant relationship between physical activity and the direct or indirect reduction of depression symptoms (Babyak et al, 2000; Broman - Fulks et al., 2008; Dopp et al, 2012; Roh, 2016). This study confirms the results of Strawbridge et al, (2002) which found that people with a low or moderate level of physical activity are more likely to experience depression than people who maintained a high level of physical activity.

The results of this study support the view that exercise is an excellent mechanism for preventing depression. The conclusion is in the same vein with the findings of other research (Biddle, Mutrie \& Gorely, 2015; Bodin \& Martinsen, 2004; Hassmen, Koivula \& Uutela, 2002; Teychenne, Ball \& Salmon, 2008) which argue that exercise is an effective proposition for preventing and treating depression.

\section{Conclusion}

This research has shown that weekly physical activity and depression levels have a statistically significant relationship, with physical activity having a negative correlation resulting in increased rates of exercise, leading to decreased levels of depression. In 
addition, it was found that people who are more active are less likely to develop depression and participation in exercise may act as a shield against the risk of developing symptoms of depression.

\section{Conflicts of interest}

The authors declare that there are no conflicts of interest.

\section{About the Authors}

Chistine Gkatsou is with the Department of Sports Management. Her research interests focus on the study of human behavior in health related fitness. Also, she is interested in organizing sports activities aimed at improving the quality of life.

Konstantina Katsora is a graduate of English Language and Literature (NKUA) and is MSc Student in Master of Science in Sport Management and Organization of sport activities for people with disabilities. Her research interests focus on the study of people with disabilities in sports, special education and linguistics.

Stylianos Kaprinis (PhD) is a specialized educational staff, at the University of Peloponnese, Faculty of Human Movement and Quality of Life, Department of Sports Management. His research interests include sport psychology, school physical education planning and teaching students with disabilities. Moreover, his research area includes the evaluation of interventions in adapted physical activity for individuals with chronic diseases.

\section{References}

American Psychiatric Association, 2013. Diagnostic and Statistical Manual of Mental Disorders, 5th ed. Arlington, VA: American Psychiatric Publishing.

Babyak, M., Blumenthal, J., Herman, S., Khatri, P., Doraiswamy, M., Moore, K., Craighead, E., Baldewicz, T., Krishnan, R, 2000. Exercise Treatment for Major Depression: Maintenance of Therapeutic Benefit at 10 Months, Psychosomatic Medicine 62:633-638.

Beck AT, Steer RA, Brown GK, 1996. Manual for the Beck Depression Inventory-II. San Antonio, TX: Psychological Corporation.

Berger, B. G., Tobar, D, 2007. Physical activity and quality of life. In G. Tenenbaum \& R. Eklund (Eds.), Handbook on research on sport psychology, 3rd ed., Hoboken: Wiley, pp. 598-620.

Biddle, S.J.H. Mutrie, N. Gorely T, 2015. Psychology of Physical Activity: Determinants, Wellbeing and Interventions. 3rd Edition, Routledge, London.

Biddle, S., Fox, K. Boutcher, S, 2000. Physical Activity and Psychological Well-being. Rutledge. London. 
Bodin, T., Martinsen, E, 2004. Mood and self-efficacy during acute exercise in clinical depression. A randomized, controlled study. Journal of Sport \& Exercise Psychology, 26, 623-633.

Broman-Fulks, J. J., Storey, K. M, 2008. Evaluation of a brief aerobic exercise intervention for high anxiety sensitivity. Anxiety, Stress, \& Coping, 21(2), 117-128.

Celano, C.M., Huffman, J.C, 2011. Depression and cardiac disease: a review, Cardiology in review, 19, 130-142, 146-151.

Clarke, D.M., Cook, K.E., Coleman, K.J., Smith, J.C, 2006. A qualitative examination of the experience of depression in hospitalized medically ill patients. Psychopathology, 39(6), 303-312.

Craft, L.,L, Perna, F., M, 2004. The benefits of exercise for the clinically depressed. Primary Care Companion, Journal of Clinical Psychiatry, 6(3), 104-111.

DiLorenzo T.M, Bargman E.P, Stucky-Ropp R, Brassington G.S, Frensch P.A, LaFontaine T, 1999 Long-term effects of aerobic exercise on psychological outcomes. Preventive Medicine, 28, 75-85.

Dimeo, F. B.,M., Varahram, I., Proest, G., Halter, U, 2001. Benefits from aerobic exercise in patients with major depression: A pilot study. British Journal of Sports Medicine, 35, 114-117.

Dopp, R. R., Mooney, A. J., Armitage, R., King, C, 2012. Exercise for adolescents with depressive disorders: A feasibility study. Depression Research and Treatment, 2012, 145-147.

Ekeland, E., Heian, F., Hagen, K. B, 2005. Can exercise improve self-esteem in children and young people? A systematic review of randomised controlled trials. British Journal of Sports Medicine, 39(11), 792-798.

Gary R., Dunbar, S., Higgins, M., Musselman, D. \& Smith, A, 2010. Combined exercise and cognitive behavioral therapy improves outcomes in patients with heart failure. Journal of Psychosomatic Research, 69, 119-131.

Godin, G, 2011. The Godin-Shephard leisure-time physical activity questionnaire. Health \& Fitness Journal of Canada, 4(1), 18-22.

Godin, G., Shephard, R. J, 1985. A simple method to assess exercise behavior in the community. Canadian Journal of Applied Sport Sciences, 10, 141-146.

Guszkowska, M, 2004. Effects of exercise on anxiety, depression and mood. Psychiatria Polska, 38 (4) 611-620.

Hagger, M.,S., Chatzisarantis, N., Biddle, S.J, 2001. The influence of self-efficacy and past behaviour on the physical activity intentions of young people. Journal of Sports Sciences, 19 (9), 711-725.

Happel, C., Steele, A.D., Finley, M.J., Kutzler, M.A., Rogers, T.J, 2008. Damgoinduced expression of chemokines and chemokine receptors: the role of TGF-beta1, Journal of Leukocyte Biology, 83 (4), 956-63.

Hassmén, P., Koivula, N., Uutéla, A. (2002). Physical Exercise and Psychological WellBeing: A Population Study in Finland, Preventive Medicine, 30(1), 17-25. 
Hellenic Statistical Authority, 2016. Health Interview Survey, www.statistics.gr/en/statistics Accessed 11/11/2020.

Jonsson, U., Bohman, H., Hjern, A., von Knorring, L., Olsson, G., von Knorring, A.L, 2010. Subsequent higher education after adolescent depression: a 15- year follow-up register study, Eur Psychiatry, 25: 396-401.

Landers D., Arent, S, 2007. Physical activity and mental health. In G. Tenenbaum, R. Eclund (Eds.), Handbook of sport psychology John Wiley \& Sons Inc, New Jersey, pp. 469-491.

Leppanen, J.M, 2006. Emotional information processing in mood disorders: A review of behavioral and neuroimaging findings. Current Opinion in Psychiatry, 19, (1) 3439.

LeUnes, A. (2008). Sport psychology (4th ed.). Psychology Press, 44-49.

Netz, Y., Wu, M.-J., Becker, B. J., Tenenbaum, G, 2005. Physical activity and psychological well-being in advanced age: A meta-analysis of intervention studies. Psychology and Aging, 20(2), 272.

Olson, R.L., Brush, C.J., Ehmann, Alderman B.L, 2017. A randomized trial of aerobic exercise on cognitive control in major depression, Clinical Neurophysiology, 128 (6), 903-913.

Osborn D, 2001. The poor physical health of people with mental illness. West Journal of Medicine, 175(5): 329-332.

Paluska S, Schwenk T, 2000. Physical Activity and Mental Health: Current Concepts. Sports Medicine, 29(3):167-180.

Raphael, B, 2000. A Population Health Model for the Provision of Mental Health Care, Publication, Reynolds R., Managing depression through needlecraft creative activities: a qualitative study, The Art in Psychotherapy, 21-29.

Richardson C, Faulkner G, Mc Devitt J, Skrinar G, Hutchinson D, Piette J. 2005. Integrating Physical Activity into Mental Health Services for Persons with Serious Mental Illness. Psychiatric Service, 56 (3):324-331.

Roh S.Y, 2016. Effect of a 16-week Pilates exercise program on the ego resiliency and depression in elderly women, Journal of Exercise Rehabilitation 12(5):494-498.

Sadock, B. J., Sadock, V. A., \& Ruiz, P, 2015. Kaplan \& Sadock's synopsis of psychiatry: behavioral sciences/clinical psychiatry (11th Ed) Philadelphia: Wolters Kluwer.

Salmon, P. 2000. Effects of physical exercise on anxiety, depression and sensitivity to stress: A unifying theory. Clinical Psychology Review, 21(1) pp 33-61.

Strawbridge, W., J., Deleger, S., Roberts, R., E., Kaplan, G., A. 2002. Physical activity reduces the risk of subsequent depression for older adults. American Journal of Epidemiology, 156(4), 328-334.

Teychenne M, Ball K, Salmon J. 2008. Physical activity and likelihood of depression in adults: a review. Preventive Medicine, 46 (5):397-411.

Theodorakis I, 2016. Exercise, Mental Health and Quality of Life, Kyriakidis Bros, Thessaloniki (in Greek). 
W.H.O (2017) Depression and Other Common Mental Disorders: Global Health Estimates, Geneva: World Health Organization, License: CC BY-NC-SA 3.0 IGO.

W.H.O, 2009.

Depression,

www.who.int/mental health/management/depression/definition/en, Accessed 14.11.2020.

W.H.O, 2012. Depression: A Global Public Health Concern. https://www.who.int/mental health Accessed 14.11.2020 .

Weinberg, R., S, Gould, D. 2011. Exercise and Psychological Well-Being. In Foundations of sport and exercise psychology 5th ed. Champaign IL: Human Kinetics, 397-415.

Wipfli, B., Landers, D., Nagoshi, C, Ringenbach, S. 2011. An examination of serotonin and psychological variables in the relationship between exercise and mental health. Scandinavian Journal of Medicine and Science in Sports, 21, 474-481. 
Creative Commons licensing terms

Authors will retain the copyright of their published articles agreeing that a Creative Commons Attribution 4.0 International License (CC BY 4.0) terms will be applied to their work. Under the terms of this license, no permission is required from the author(s) or publisher for members of the community to copy, distribute, transmit or adapt the article content, providing a proper, prominent and unambiguous attribution to the authors in a manner that makes clear that the materials are being reused under permission of a Creative Commons License. Views, opinions and conclusions expressed in this research article are views, opinions and conclusions of the author(s). Open Access Publishing Group and European Journal of Physical Education and Sport Science shall not be responsible or answerable for any loss, damage or liability caused in relation to/arising out of conflict of interests, copyright violations and inappropriate or inaccurate use of any kind content related or integrated on the research work. All the published works are meeting the Open Access Publishing requirements and can be freely accessed, shared, modified, distributed and used in educational, commercial and non-commercial purposes under a Creative Commons attribution 4.0 International License (CC BY 4.0). 